\title{
O MERCADO DE ARTEFATOS AKWÊ-XERENTE: CONTEXTOS URBANOS EM PERÍODO DE COVID-19
}

MARIANE FREIESLEBEN ${ }^{1}$

IFTO, BRASIL

http://orcid.org/0000-0001-7213-3775

JANAINA SIKWATKADI CALIXTO XERENTE ${ }^{2}$

UFT, BRASIL

https://orcid.org/0000-0003-0120-8228

ALEX PIZZIO DA SILVA ${ }^{3}$

UFT, BRASIL

https://orcid.org/0000-0001-7181-6355

REIJANE PINHEIRO DA SILVA ${ }^{4}$

UFT, BRASIL

https://orcid.org/0000-0002-0636-9795

\begin{abstract}
RESUMO: $A$ comercialização de artefatos/artesanatos do povo Akwê-Xerente para muitos se apresenta como principal recurso de geração de renda. Muitos indígenas dedicam parte do seu tempo a elaborar e produzir especificamente para este fim. São diversas as práticas e os significados envolvidos na produção e no intercâmbio (monetário ou escambo) desses objetos. Ao mesmo tempo, são constantes as demandas de articulação ao mercado - sejamrelacionadas ao preço imposto como ao enfrentamento da pandemia de COVID-19-, encontrando-se muitas dificuldades para que esse povo seja ouvido. Considerando o contexto etnográfico do povo AkwêXerente, por meio da pesquisa bibliográfica, documental e da história oral, discutem-se os processos de produção, comercialização dos artefatos/artesanatos, e examina-se também esse contexto no periodo da pandemia, considerando a voz desses produtores. O argumento central aponta que esse povo tem sido inserido no mercado sem o apoio necessário para o desenvolvimento e reprodução de sua economia.
\end{abstract}

PALAVRAS-CHAVE: artesanato/artefato, comércio, indígena, pandemia.

ABSTRACT: The commercialization of artifacts / handicrafts of the Akwe-Xerente people for many presents itself as the main resource of income generation. Many indigenous people devote part of their time to elaborating and producing specifically for this purpose. There are several practices and meanings involved in the production and exchange (monetary or barter) of these objects. At the same time, there are constant demands for articulation with the market, whether

\footnotetext{
${ }^{1}$ Doutoranda em Desenvolvimento Regional na Universidade Federal do Tocantins (UFT). E-mail: mariane@ifto.edu.br

${ }^{2}$ Graduada em Enfermagem na Universidade Federal do Tocantins - UFT, Liderança Jovem indígena do povo Akwê-Xerente. E-mail: janaenfer.18@gmail.com

${ }^{3}$ Coordenador e professor do Programa de Pós-Graduação de Desenvolvimento Regional da Universidade Federal do Tocantins (UFT). E-mail: alexpizzio@gmail.com

${ }^{4}$ Professora adjunta III da Universidade Federal do Tocantins. E-mail: reipinheiro@mail.uft.edu.br 
EspaçoAmeríndio

related to the imposed price or to coping with the COVID-19 pandemic, with many difficulties for these people to be heard. Considering the ethnographic context of the Akwê-Xerente people, through bibliographic, documentary research and oral history, the processes of production, commercialization of artifacts / handicrafts are discussed, and this context is also examined in the period of the pandemic, considering the voice of these producers. The central argument points out that these people have been inserted in the market without the necessary support for the development and reproduction of their economy.

KEYWORDS: crafts / artifact, business, indigenous, pandemic. 


\section{Introdução}

Componente da economia criativa, o artefato ou artesanato indígena é um produto cobiçado desde o processo de colonização europeia, quando os nativos dessas regiões foram nomeados de índios ${ }^{5}$. Esses bens constituem um conjunto diversificado, pautado na criatividade, no talento e na habilidade individual que, de acordo com Duque (2015), refletem elementos da economia solidária e relacionam-se com o conhecimento tradicional, que viabiliza e amplia a participação dos cidadãos na vida política (REIS, 2008), além de contribuir para a retomada do seu espaço, que por meio do design social inclui e valoriza o artefato/artesanato da comunidade indígena no território local, nacional e internacional.

São processos que inserem os povos indígenas na economia do mercado, mas que são marcados por transformações socioculturais, implicando mudanças significativas no próprio sistema tradicional que é fundamentado nos princípios de reciprocidade, redistribuição e no intercâmbio de bens. Essa inserção na economia de mercado confronta dois modelos de comercialização: o das sociedades indígenas, muitas vezes denominadas arcaicas por estarem ligadas a obrigações sociais, rituais, políticas e econômicas (VERETA-NAHOUM; GUIMARÃES, 2017), e o da sociedade colonial, na qual temos um sistema capitalista extremamente voraz, no que se refere às relações comerciais e de lucro, subordinado à lógica do sistema financeiro, chamada lógica neoliberal ${ }^{6}$.

Essa lógica neoliberal "consequentemente, só concebe o sistema mundo moderno do ponto de vista de seu próprio imaginário, mas não do ponto de vista do imaginário conflitivo que surge com e da diferença colonial" (MIGNOLO, 2005, p. 36). Uma ideia que coloca a modernidade a serviço exclusivo da Europa, inferiorizando e subestimando a identidade latino-americana (DUSSEL, 2005). Esquecendo-se que foi a colonização, a fonte original que definiu e reproduziu nesses povos colonizados os elementos básicos desta sociedade dependente e periférica (QUIJANO, 2005).

Os artefatos/artesanatos indígenas englobam adornos, cestarias ${ }^{7}$, cerâmicas, flautas e chocalhos (DUQUE, 2015; SOARES; DEBORTOLI, 2018). Entende-se que no mundo contemporâneo essa produção artesanal constitui-se como uma ferramenta importante de visibilidade social e alcance na luta pelos direitos indígenas. Os espaços de venda dos artefatos/artesanatos, representam seus locais de visibilidade, onde comercializam seus produtos, muitas vezes sem qualquer apoio do poder público, classificados como vendedores ambulantes informais, tornandoos invisíveis no meio urbano no tocante à efetivação de seus direitos, um movimento de fuga da imitação e subversão (QUIJANO, 2005).

\footnotetext{
5 Identidade imposta pelo colonizador, associada à materialidade das relações sociais e pessoais (QUIJANO, 2005).

${ }^{6}$ Doutrina política que defende a liberdade absoluta do capitalismo e mínima intervenção do Estado no plano jurídico e econômico.

${ }^{7}$ Cestos produzidos com folhas de palmeiras.

FREIESLEBEN, Mariane; XERENTE, Janaina Sikwatkadi Calixto; SILVA, Alex Pizzio da; SILVA, Reijane Pinheiro da. O mercado de artefatos Akwê-Xerente: Contextos urbanos em período de covid-19. Espaço Ameríndio, Porto Alegre, v. 15, n. 2, p. 182-205, mai./ago. 2021.
} 
Ali, estereotipados pela sociedade, que muitas vezes não os qualifica como povos indígenas, por estarem na cidade, e introduzidos no mundo capitalista comercial, percebe-se um povo limitado, seja pela perda dos direitos imposta pela colonização, como pela perda quantitativa de seus espaços ou da qualidade ambiental que dispunham anteriormente (ALBUQUERQUE, 2015). Ao analisar a condição imposta pela sociedade aos povos indígenas, de povos estereotipados, conformase a subjugação desse povo obtendo o máximo daquilo que deles pode ser extraído.

Nesse processo de consolidação hegemônica da civilização que submeteu esses povos, cuja matriz é a alienação e subjugação, construíram-se, historicamente, relações de violência e negação, que se manifestam no racismo cotidiano e impõe para esses povos impactos que afetam seus territórios, seus sistemas produtivos e seus sistemas de saúde. Como, por exemplo,a pandemia do Covid-19 no ano de 2020, assim declarada pela Organização Mundial de Saúde (OMS), em 11 de março do mesmo ano, impondo temos um momento histórico difícil, que afeta indistintamente a todos e a todas (MOREIRA et al, 2020). Conforme Silva \& Gracio (2020) alertam, os agravos de saúde tendem a repetir os extermínios que marcam a histórica relação entre os povos indígenas e o Estado brasileiro, que insiste em não construir um diálogo afetivo com esses povos.

É indispensável entender os caminhos e as tramas envolvidas nessa relação comercial, relacionadas a direitos culturais, de expressão e de preservação. Compreender as políticas públicas e os marcos regulatórios que defendem o desenvolvimento, a inclusão social e a sustentabilidade. Nesse processo artefato/artesanato indígena assume uma face produtivamente econômica, de inclusão e resistência à opressão. Faz-se necessário desnaturalizá-la, conhecer as relações sociais de troca, o comércio, avançar sobre as fronteiras dos circuitos demarcados sob um conjunto de laços interpessoais significativos que adotam sentidos nas transações econômicas e nos meios de troca associados a eles, tornandose imperativo também uma análise sob a perspectiva e significado atribuídos pelo agente (VERETA-NAHOUM; GUIMARÃES, 2017).

Considerando os contextos etnográficos do povo indígena Akwêxerente, iremos discutir aspectos dos processos destas comunidades na economia de mercado por meio da venda de artefatos/artesanatos, analisando as implicações nas formas de produção, intercambio, consumo e comercialização, assim também como as transformações que ocorreram nessa comercialização com a pandemia do covid-19 na lógica do mercado. As reflexões aqui apresentadas se basearam em estudos bibliográficos e na técnica da história oral ${ }^{8}$ para coleta das informações etnográficas. Além da pesquisa bibliográfica sobre os temas da produção cultural indígena para a contextualização da discussão proposta, também conduzimos uma pesquisa documental de leis, políticas e programas oficiais voltados a comercialização de artefatos/artesanatos indígenas no

\footnotetext{
${ }^{8}$ Método de investigação científica, que possui técnica de produção e tratamento de depoimentos gravados, dando voz a personagens sociais que, na construção da memória coletiva, possuem baixo índice de participação (ALBERTI, 2005). 
Brasil e no Estado do Tocantins, bem como das políticas e transformações ocorridas com a pandemia da covid-19, a fim de identificar o tratamento oferecido a esses povos.

A amostra da pesquisa foi limitada pela necessidade de distanciamento social imposta pela pandemia do COVID-19, e compreende as artesãs das seguintes Aldeias: Rio Preto, Sucupira, Brejo Comprido, Boa Vista, Sangradoura, Vão Grande, localizadas na Terra Indígena Xerente. Em relação aos nomes dos sujeitos nas narrativas, entrevistas e informações, utilizaremos as iniciais dos nomes das aldeias, quando semelhantes utilizamos também a primeira letra do nome da entrevistada, seguidos do termo Xerente.

No próximo item, iremos caracterizar o povo Akwê-xerente no contexto etnográfico. Posteriormente, serão apresentados a patrimonialização e regularização do comércio dos artefatos/artesanatos indígenas no Brasil e no Tocantins. Nos itens seguintes, iremos descrever a forma de produção dos artefatos/artesanatos e como esses povos realizam a geração de renda e os canais de comercialização e resistência por meio dos artefatos/artesanatos no Estado do Tocantins, respectivamente. Por último, teceremos as considerações finais.

\section{Caracterização do contexto etnográfico}

De acordo com os estudos de Darcy Ribeiro (1996), os Akwê viviam nos sertões do interior do Brasil, mencionados como uma das tribos do Brasil Central, pertencentes ao tronco linguístico chamado Jê Central. $\mathrm{O}$ primeiro contato com a população não indígena ocorreu por volta de 1785 , e as relações eram pacíficas com o governo da capitania de Goiás (RIBEIRO, 1996). Ao longo do tempo esse grupo permaneceu na bacia do médio Tocantins.Contudo, para fugir dos grupos invasores, foram afastando-se até chegarem à região de Tocantínia, onde residem atualmente (OLIVEIRA-REIS, 2001; ARAUJO, 2016; LIMA, 2017; RAPOSO, 2019).

Entre os indígenas a terra é um bem coletivo e comunitário, dividida e habitada de acordo com a organização cultural e específica de cada povo. Com a aprovação da Constituição de 1988, após uma grande mobilização indígena no Brasil, os povos indígenas passaram a lutar para efetivação e acesso a esses direitos, permanecendo no seu território e mantendo viva a língua e a cultura, que compreende formas de pensar, e habitar, e se relacionar com o território. A constituição, no artigo citado abaixo, reconhece os direitos originários às terras, tradicionalmente ocupadas pelos povos indígenas brasileiros:

Art. 231. São reconhecidos aos índios sua organização social, costume, línguas, crenças e tradições, e os direitos originários sobre as terras que tradicionalmente 
ocupam, competindo à União demarcá-las, proteger e fazer respeitar todos os seus bens.

$\S 1$ São terras tradicionalmente ocupadas pelos índios as por eles habitadas em caráter permanente, as utilizadas para suas atividades produtivas, as imprescindíveis à preservação dos recursos ambientais necessários ao seu bem-estar e as necessárias à sua reprodução física e cultural, segundo seus usos, costumes e tradições (BRASIL, 1988).

As relações ambientais, políticas, sociais e econômicas tem mudado nos territórios indígenas, que estão vivendo e se organizando dentro e fora do seu território, reelaborando suas vidas e culturas a partir dos desafios impostos pelos contanto com a sociedade nacional, estadual e municipal, principalmente na cidade de Tocantínia (LIMA, 2017; RAPOSO, 2019).

É possível perceber conflitos entre os órgãos administrativos e o povo Akwê-xerente, como, por exemplo, o recurso anual relacionado ao imposto ambiental ${ }^{9}$, o Imposto sobre Circulação de Mercadorias e Serviços - ICMS ecológico ${ }^{10}$, que a Prefeitura de Tocantínia recebe, mas sobre o qual alguns Xerentes de determinadas aldeias não se sentiram contemplados na tomada de decisão, e nos benefícios dela resultantes. Por dois ou três anos a prefeitura de Tocantínia utilizou o ICMS ecológico com a brigada indígena contra o fogo.Contudo, depois que o Instituto Brasileiro do Meio Ambiente e dos Recursos Naturais Renováveis - IBAMA - assumiu a responsabilidade em subsidiar as brigadas de combate ao fogo, a prefeitura não tem prestado esclarecimentos sobre como esse recurso vem sendo investido. Ademais, os Xerentes defendem que os impostos não estão sendo utilizados para as questões ambientais da área indígena, conteúdo para o qual ele foi criado (ARAUJO, 2016).

Outro problema que eles enfrentam, relaciona-se à questão do lixo, cuja coleta não é realizada de forma satisfatória (ARAUJO, 2016), um problema que deve ser associado aos novos costumes atribuídos pelo consumo de produtos industrializados provenientes da sociedade envolvente, dando ênfase aos traços de transformação e dependência criados nesse povo pela cultura ocidental.

A cosmologia" dos Akwê-xerente relaciona-se às experiências e saberes humanos, animais, e sobrenaturais absorvidos com a totalidade da natureza, relacionando dois mundos, o material e o espiritual sob uma visão holística. É uma sociedade patrilinear, que compreende que as

\footnotetext{
${ }^{9}$ Comportamentos nocivos para a saúde do planeta que são taxados. Partem de um simples princípio que a pessoa ou grupo que contaminou paga pelo prejuízo gerado, e são essenciais para frear as mudanças climáticas.

${ }^{10}$ Mecanismo tributário que possibilita aos municípios acesso a parcelas maiores que àquelas que já têm direito dos recursos financeiros arrecadados pelos Estados através do Imposto sobre Circulação de Mercadorias e Serviços - o ICMS - devido ao atendimento de determinados critérios ambientais estabelecidos em leis estaduais de proteção e preservação ambiental. Não é um novo imposto, mas sim a introdução de novos critérios de redistribuição de recursos do ICMS, que reflete o nível da atividade econômica nos municípios em conjunto com a preservação do meio ambiente.

${ }^{11}$ Explicação da ordem das coisas; explicação da origem e evolução do universo. 
crianças pertencem à família do pai.Culturalmente, esse povo vivia da caça, pesca, coleta e das plantações de roças de toco e vazante.Contudo, hoje seu território é composto por escolas, igrejas, onde acontecem festividades religiosas (católicas e protestantes), como também a tradicional festa cultural que demonstra a resistência deste povo (LIMA, 2017). É um povo caracterizado pelo dualismo, baseado na divisão sociocosmológica das metades Doí e Wahirê, que significam Sol e Lua respectivamente (SOARES; DEBORTOLI, 2018).

A organização atual foi motivada por fatores históricos que contribuíram para a criação de pequenas aldeias por todo o território, uma forma de protegê-la e vigiá-la, promovendo a retirada dos fazendeiros e posseiros. Embora, de certa forma, esta nova organização tenha dificultado determinadas práticas e rituais como, por exemplo, o Dãsipê $\hat{~}^{12}$, principal festa deste povo, tendo em vista que antes os clãs possuíam três metades e agora somente duas em sua maioria (ARAUJO, 2016).

Devido às transformações advindas do contato prolongado com a sociedade nacional, hoje eles não vivem somente da caça, coleta, criação ou plantio. Alguns são funcionários públicos, recebem auxílios do governo, como também produzem artefatos/artesanatos para revenda ou escambo na cidade. Para algumas famílias funciona como um complemento da renda. Para outras a principal renda do mês. Esse dinheiro faz-se necessário para que eles tenham acesso a bens que não produzem, mas necessitam consumir (LIMA, 2017; SOARES; DEBORTOLI, 2018; RAPOSO, 2019). "Três são as formas de subsistência: a familiar; a coleta e a venda de artesanatos e benefícios previdenciários pagos aos anciões; e a renda dos Xerente que são funcionários do governo estadual ou da FUNAI" (ARAUJO, 2016, p. 165).

$\mathrm{O}$ território indígena dos Akwê-xerente faz divisa com as cidades de Pedro Afonso, Rio Sono, Tocantínia, e Aparecida do Rio Negro (ver figura 1). No entanto, é na cidade de Tocantínia que se encontra a maior concentração de indígenas. Quase $50 \%$ da população é composta por indígenas e eles também participam da vida político-partidária do município. Ainda assim, sofrem discriminação no cotidiano da cidade, o tratamento em relação aos indígenas é distante, e com certo descaso por parte de algumas pessoas (MESQUITA, 2015; LIMA, 2017).

"Em Tocantínia, às segundas-feiras, ocorre uma feira onde os indígenas vendem seus artesanatos, principalmente os de Capim Dourado. Nesta feira acontece o que se chama de 'escambo', a troca de produto por produto" (LIMA, 2017. p.147). Apesar disso, de acordo com a autora, é na cidade de Miracema do Tocantins que eles resolvem questões relacionadas a bancos, empréstimos e outros negócios, contribuindo para a circulação de dinheiro neste município, ou seja, por meio de suas atividades beneficiam a renda de dois municípios.

De acordo com Silva \& Grácio (2020), falta a esse povo a possibilidade de escolher o caminho da autossutentabilidade econômica

\footnotetext{
${ }^{12}$ Festa que geralmente ocorre nos meses de abril e julho, na qual realizam a corrida da tora, que representa a identidade e alteridade do povo, podendo ser individual ou em grupo. 
e social, pois, na relação com o Estado, não se consideram as epistemologias que orientam as formas de ocupar e pensar seus territórios e a sociodiversidade que os caracteriza.

Figura 1 - Mapa populacional das aldeias Akwê-xerente.

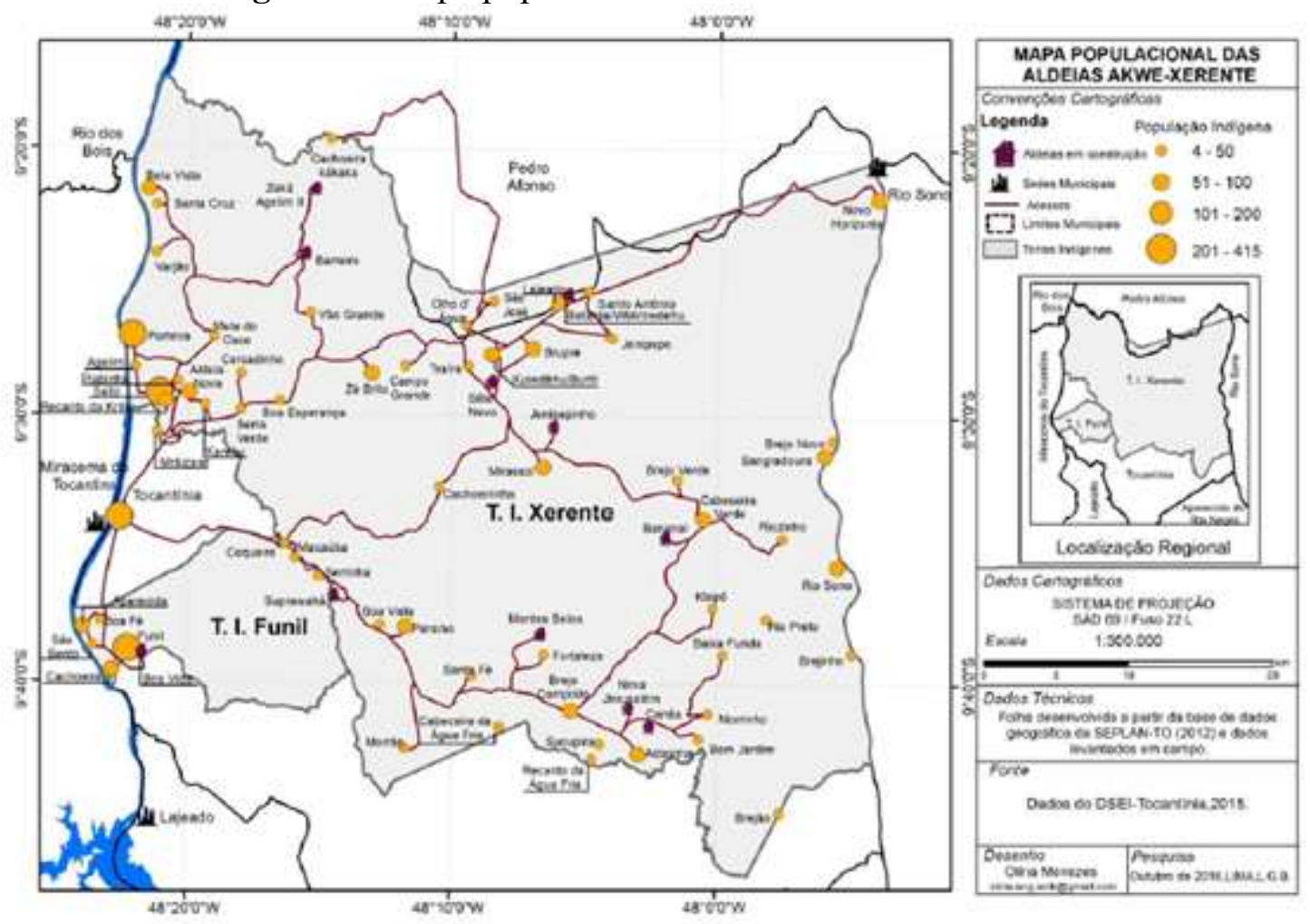

FONTE: Lima, 2017.

Foram identificadas aproximadamente 81 aldeias ao longo das pesquisas bibliográficas e de campo, e utilizamos a organização proposta pela Fundação Nacional do Índio (FUNAI) que apresenta as aldeias em 5 grandes regiões: Região PI Xerente, Região do Rio Sono, Região do Funil, Região Brejo Comprido, Região do Brupé. A Terra Indígena Funil e Área Grande Xerente compõem a totalidade do território dos Akwê-Xerente (ARAUJO, 2016; LIMA, 2017; RAPOSO, 2019) (ver figura 1).

Tabela 1 - aldeias que utilizam o artesanato como fonte de renda

\begin{tabular}{|l|c|c|c|}
\hline $\begin{array}{c}\text { CINCO GRANDES REGIÕES - IBGE } \\
\text { ALDEIA PRINCIPAL }\end{array}$ & $\begin{array}{c}\text { QUANTIDADE } \\
\text { DE ALDEIAS } \\
\text { ORIGINADAS }\end{array}$ & $\begin{array}{c}\text { RENDA } \\
\text { PRINCIPAL }\end{array}$ & $\begin{array}{c}\text { COMPLEMENTA } \\
\text { A RENDA }\end{array}$ \\
\hline TERRA INDIGENA FUNIL & 6 & - & 1 \\
\hline ÁREA GRANDE XERENTE - PORTEIRA ${ }^{1}{ }^{2}$ & 19 & 4 & 6 \\
\hline DO RIO SONO & 11 & 2 & 4 \\
\hline DO BRUPRÉ & 14 & 6 & 1 \\
\hline DO BREJO COMPRIDO ${ }^{2}$ & 23 & 4 & 10 \\
\hline
\end{tabular}

FONTE: Lima, 2017 (Adaptação e complementação dos autores).

1. Possui comprador que vem de outro Estado: Aldeia Recanto Krité.

2. Troca o artesanato por roupas: Aldeia Varjão e Aldeia Brejo Comprido. 
Seguem, de acordo com as regiões, as aldeias utilizadas no estudo:

- Região Porteira (Aldeia Vão Grande);

- Região Rio Sono (Aldeia Rio Preto; Aldeia Sangradoura);

- Região Brejo Comprido (Aldeia Sucupira, Aldeia Brejo Comprido, Aldeia Boa Vista).

\section{A patrimonialização dos indígenas e a regularização da comercialização de sua produção artesanal}

Em 1910 foi criado o Serviço de Proteção ao Índio e Localização dos Trabalhadores Nacionais (SPILTN), subordinado ao Ministério da Agricultura, no governo de Nilo Peçanha. Uma de suas funções, em nível nacional, era prestar assistência à população indígena brasileira. $\mathrm{Na}$ prática, o Serviço de Proteção ao Índio (SPI), desenvolveria ações de caráter meramente tutelar, além da construção de dois postos na área Xerente. Logo nos primeiros anos de sua criação, foi delineada a intervenção fundiária, de forma que ocorresse o reconhecimento da posse indígena da terra, como também a dimensão estratégica do trabalho com os índios (LIMA, 1992).

Em 1940, ocorreu uma reformulação na política indigenista e o SPI passou a ser denominado Fundação Nacional do Índio (FUNAI). Contudo, não se desvinculou de seu caráter de órgão tutelar, para demarcar e homologar as Terras Indígenas (TI). Somente em 1967 a FUNAI passou de fato por uma reformulação na política indigenista, com a implantação de inspetorias regionais localizadas nas principais capitais e de postos indígenas nas localidades onde habitavam populações indígenas. Por meio dos Postos de Assistência, Nacionalização e Educação (PIN), os índios eram "ensinados" a ler e escrever na língua portuguesa e aprendiam ofícios como: oleiro, carpinteiro, bordado, costura entre outros (ROCHA, 2010).

O povo Akwê-xerente tem seu território numa área que totaliza em 183.245,902 hectares. Porém, é uma terra que se divide em duas áreas indígenas, na qual as demarcações e os processos ocorreram em épocas e processos diferentes. A T.I. Xerente possui uma extensão de $167.542,105$ hectares e foi delimitada pelo Decreto $\mathrm{N}^{\circ}{ }^{\circ} 71.107$, de 14 de setembro de 1972, demarcada pelo Decreto N. ${ }^{\circ} 76.999$, de 8 de janeiro de 1976, e homologada pelo Decreto N. ${ }^{\circ} 97.838$, de 16 de junho de 1989. Já a T.I. Funil foi delimitada pela Portaria n. ${ }^{\circ} 1.187 / E / 82$, de 24 de fevereiro de 1982, e homologada pelo Decreto n. ${ }^{\circ} 269$, de 29 de outubro de 1991, e possui uma extensão de 15.703,797 hectares. Desta forma, a T.I. é uma propriedade estatal (da União), um espaço planejado pelo Estado de acordo com as estratégias políticas em questão, no qual a população indígena possui o direito de posse da área delimitada pela ação estatal.

Além do direito ao território indígena, a Constituição de 1988 também garante $\mathrm{o}$ direito de eles exercerem a própria cultura, oferecendo-Ihes a possibilidade de recorrerem à Justiça para defenderem 
seus direitos e interesses, competindo ao Ministério Público interpor em todos os atos do processo. De acordo com a Lei $\mathrm{n}^{\circ} 6.001$ de 19 de dezembro de 1973, que dispõe sobre o Estatuto do Índio, a União, Estados e Municípios devem proteger e preservar o direito das comunidades indígenas, respeitando suas particularidades e assegurando a livre escolha dos seus meios de vida e subsistência e o respeito aos seus patrimônios culturais, valores artísticos e meios de expressão.Já a convenção 169 da Organização Internacional do Trabalho ${ }^{13}$ (OIT), de 17 de junho de 1989, foi promulgada no Brasil pelo Decreto $n^{0} 5.051$ de 19 de abril de $2004^{14}$ e consolidada pelo Decreto $n^{0} 10.088$ de 05 de novembro de 2019.

Entretanto, não foram observados ao longo do Estatuto, Decreto ou Lei mecanismos efetivos de aplicação dessas proteções. Na verdade, podemos observar que os indígenas sofrem com a dificuldade de acesso a esses mercados, a participação em feiras, seja relacionada à regularização da produção e venda ou à falta de infraestrutura, como transporte e comunicação. Percebe-se certo descaso relacionado a iniciativas por parte do poder público em áreas predominantemente habitadas por artesões indígenas, episódio que tem contribuído para inúmeros artesões indígenas não receberem potenciais benefícios. Os Jogos Mundiais dos PovosIndígenas ${ }^{15}$, realizadosno Estado do Tocantins, na cidade de Palmas em outubro de 2015, foram um importante investimento, mas desde essa iniciativa pouco tem sido feito no âmbito federal, estadual e municipal que esteja relacionado à promoção da sustentabilidade e comercialização dos produtos artesanais indígenas. No Estado do Tocantins, na cidade de Tocantínia, a prefeitura realiza na Praça Valperino Gomes de Oliveira, localizada na área central da cidade mais conhecida como Praça Brasília, o "carnatoca", um carnaval fora de época que busca prestigiar o comércio do artesanato indígena, que ocorre todos os anos no primeiro final de semana do mês de julho. Contudo, em época de pandemia $^{16}$ o evento não foi realizado. Afinal, como esse povo comercializou sua produção artesanal?

Além das feiras periódicas, onde e como os indígenas comercializam seus produtos diariamente, visto que num sistema capitalista a busca pela sobrevivência é diária? Entende-se também que o acesso desses povos por via terrestre se faz por estradas precárias em relação à infraestrutura, ocasionando uma estrita logística para participação em feiras ocasionais. Mas e no dia a dia, como fica? Ademais, as devidasvaloração ou desvalorização dos produtos artesanais indígenas

\footnotetext{
${ }^{13}$ Instrumento internacional atualizado e abrangente que relaciona as condições de vida e trabalho dos indígenas. Trata-se de um acordo internacional ratificado pelo Estado com caráter vinculante, no qual uma decisão tomada em um tribunal sobre certo processo passa a valer para os demais que tenham uma questão idêntica.

${ }^{14}$ Afirma executar e cumprir a Convenção 169 da OIT inteiramente como nela se contem.

${ }^{15}$ Idealizado pelo Ministério do Esporte, Comitê Intertribal (ITC), Programa das Nações Unidas para o Desenvolvimento (PNUD) e pela Organização das Nações Unidas para a Educação, a Ciência e a Cultura (UNESCO) (ROQUE et al, 2017).

${ }^{16}$ Pandemia de Covid-19 - (SARS-COV-2) anunciada ao Brasil em 26 de fevereiro de 2020, mas declarada mundial pela OMS em março de 2020, a partir da qual a recomendação foi o isolamento e fechamento do comércio, permitindo somente os serviços essenciais.
} 
também precisam de certificação de origem para atestar a procedência deste produto, e seus bônus - como financiamento ofertados pelos bancos ou seu ônus para o acesso a esse benefício -são compostos por uma regulamentação, que gera taxas e impostos,que ficam a cargo dos indígenas. Mas como, se esse povo mal consegue sobrevier com essa produção e muitos ainda praticam escambo com esse produto?

O governo Federal, por meio da FUNAI, busca a promoção do etnodesenvolvimento com programas de gestão territorial e ambiental das terras indígenas focalizando a segurança e soberania alimentar e nutricional, implementando, para isso, várias ações, como a comercialização da produção de artesanato. Através do Programa Artindia, que é elaborado e executado pela Diretoria de Administração e Gestão - DAGES -, cujo objetivo principal é resgatar, promover, fortalecer e divulgar as manifestações artísticas e culturais das sociedades indígenas brasileiras por meio da comercialização dos artesanatos indígenas através de financiamentos de projetos/atividades de revitalização, como também por meio de planos de recuperação do estoque e acervo do depósito Artindia e, desta forma, dar visibilidade às culturas indígenas. No museu do Índio/Renda Indígena se utilizam diferentes estratégias de divulgação dos produtos artesanais de diferentes etnias (RAG/FUNAI, 2018). Entretanto, ao longo de todo o texto não encontramos nada relacionado diretamente ao artesanato AkweXerente ou sobre o Município de Tocantínia.

Ainda que a Constituição de 1988 "garanta" direitos inalienáveis aos povos indígenas, como não regulamenta tais direitos, torna ineficaz o comércio do artesanato indígena. E de acordo com Jesus (2017):

O próprio programa Artíndia veio sendo gradativamente desmontado, com o fechamento de lojas, a nãorealização de compras e captação em comunidades indígenas e ameaças de punições para índios que confeccionem e comercializem objetos proibidos pelo IBAMA (JESUS, 2017, pag. 355).

O artesanato, em si, é uma atividade que possui demandas específicas dos artesões.Desta forma, o governo Federal criou o Decreto $\mathrm{n}^{\circ} 1.508$ de 31 de maio de 1995 para submeter o artesanato brasileiro ao Secretário de Comércio e Serviços do Ministério do Desenvolvimento, Indústria e Comercio Exterior, que cria a Portaria SCS/MDIC n 29 em 05 de outubro de 2010, tornando pública a base conceitual do artesanato brasileiro, de forma a padronizar e estabelecer os parâmetros de atuação do Programa do Artesanato Brasileiro - PAB em todo o território nacional. E por meio da Portaria $n^{\circ} 1.007-S E I$ de 11 de junho de 2018, instituiu o programa e criou a Comissão Nacional do Artesanato, cujo objetivo era instituir a base conceitual do artesanato brasileiro. Mas pouco ou quase nada desses decretos ou portarias, interferem ou dialogam especificamente com as questões práticas e necessárias da produção e comercialização do artesanato indígena, somente em reconhecimento à sua produção artesanal e execução da técnica da serigrafia para os povos indígenas. 
O governo do Estado do Tocantins, que possui conhecimento da baixa oferta de postos de trabalho para os indígenas, afirma apoiar projetos que contemplem as etnias tocantinenses, citando como exemplo o Aldeia cidadã, que atua através de cursos sobre as danças e músicas. Contudo, foi por meio do financiamento do Banco Mundial que o Projeto BMG Brasil - Mecanismo de Doação Dedicado a Povos Indígenas e Comunidades Tradicionais no âmbito do Programa de Investimento Florestal - conquistou o Centro de Fortalecimento da Cultura Xerente (PORTAL TOCANTINS, 2019), que com a pandemia ainda não foi inaugurado e divulgado.

Na prática, a participação e representação dos indígenas junto à sociedade já é complexa, visto que a demanda dos indígenas, assim como dos artesões indígenas, é marginalizada, tornando a efetivação dessa atividade ainda mais difícil de atingir a visibilidade necessária que um mercado capitalista necessita, tornando a produção de artesanato indígena uma forma de defesa do modo de vida dessas populações. Criase, assim, uma rede de comércio solidário para os indígenas, mas lucrativo para os atravessadores.

\section{Modos de produção e resistência por meio do artesanato}

Os valores simbólicos e identitários são o resultado do tempo e da paciência gastos na confecção manual de um fazer individual, que exige destreza e habilidade, mas que relaciona uma cadeia social de compreensão do entorno. Desta forma, para moldar e alterar a peça produzida, transferindo a ela significados culturais, faz-se necessário todo um potencial criativo presente nos vínculos comunitários e nas suas complexidades.

A rotina nas aldeias Akwê-Xerente começa assim:

[...] o dia a dia (silêncio) daqui da minha aldeia (silêncio) ééééééé (silêncio) aaamanhecê eu levanto faço café (silêncio) eeee chamo com todas as meninas pra gente começa o nosso trabalho que é faze artesanato, o nosso dia a dia, é sempre assim, depois do café a gente iniciamos o nosso trabalho com artesanato de capim dourado (S.V.XERENTE, 2021).

Por meio da descrição da entrevistada, percebe-se a ação de rememoração quando ela utiliza o pronome possessivo minha, expressando segurança e identidade, com a experiência do domínio da realidade, por meio das pausas gramaticais regulares.Da mesma forma, é possível perceber uma tentativa de organização do pensamento, em torno do referencial que precisa ser revelado (POLLAK, 1992) -a transcrição das repetições das letras "éééééé" e das pausas em forma de silêncio representam a reprodução do discurso popular (PORTELLI, 1997).

Em outra Aldeia o "[...] dia a dia ééééé, as mulheres (silêncio) primeiro cuidando da casa (silêncio) aaaas mais velhassss trabalham na lavoura eeeee (silêncio) nós as mais jovensss fazemos artesanato no nosso 
dia a dia, depois de cuidá da casa, dos nosso filhos e maridos" (S.M.XERENTE, 2021).Aqui é possível aqui constatar o desenvolvimento de várias atividades como cuidar da casa, da lavoura, da confecção do artesanato, e dos familiares no decorrer do dia, bem como a divisão realizada entre eles na qual as mulheres também têm suas atividades distribuídas em função da idade.

O intercâmbio das experiências é refletido por meio da atividade na produção do artesanato, na qual as artesãs compartilham modos de vida, costumes, tradições e visões de mundo que ora as aproximam, ora as separam, além de modelar o sustento econômico e monetário da Aldeia. Quando perguntado como era realizada a produção:

Ééééé, (silêncio) primeiramente vai de cada região, (silêncio) na minha região, por exemplo, na região brejo comprido, (silêncio) ééé não se encontra capim dourado porque o capim dourado é encontrado na, em veredas, (silêncio) e na minha região não tem isso é um brejo né, só o nome que é brejo comprido, mas, (silêncio) o capim a gente não encontra, o capim dourado, (silêncio) e ai a gente compra, a gente vai sai pra outras aldeias, e a gente compra, (silêncio) e também, (silêncio) ééééé. Os, (silêncio) os... os não indígena, que levam capim dourado também nas aldeias e a gente compra, (silêncio) [mexe as mãos], mas para confecção de coifos e outros, e... esteiras que os ma, que as anciãs fazem, (silêncio) a gente... encontra aqui perto, aqui mesmo também, que a gente vai na mata pega, tira as, as fitas e ai confecciona mas, (silêncio) o capim dourado, a gente compra (B.C. XERENTE, 2021).

No depoimento é perceptível a quebra da tradição, quando revela que nem todas as regiões Xerentes possuem acesso ilimitado à matériaprima do capim dourado.Embora a produção do artesanato tenha se desenvolvido e pertença às características culturais desse povo, para ter acesso a esse bem é preciso comprar esse produto de outras pessoas. Ademais, é visível o desconforto da entrevistada através do silêncio e da agitação das mãos, que posteriormente encontra refúgio ao revelar o modo de produção dos côfos ${ }^{17}$, cuja matéria prima é encontrada com mais facilidade e à vontade na mata. Essa produção requer um profundo conhecimento da matéria-prima para dar cor e forma às peças produzidas e, para isso:

Por exemplo, eu vou dá um, um exemplo de, de um, de um côfo: O côfo a gente busca a palha (silêncio) traz pra casa, ai faz aaa, tece ela primeiro, bota no sol, ela seca, ai va, depois que ela fica bem sequinha, ai que a gente vai começa, é, é faze a produção dela é, é muito demorada, é muito difícil (silêncio) mas como é da gente,

\footnotetext{
17 Tipo de cesto utilizado para transportar alimentos e instrumentos de trabalho nas roças, bem como para guardar pequenos objetos. 
a gente gosta, eu gosto muito de fazer isso, é nossa cultura, é nosso costume (B.V. XERENTE, 2021).

Atividades que por meio da prática constante, além do conhecimento, deixam marcas nas mãos calejadas, por um serviço de transformação de um recurso natural em um componente estético, pois para a produção "inventamos o modelos que iremos produzir dos artesanatos, fazemos na trança, e também misturamos na fita de buriti, a pintura é realizada com casca de manga e outros tipos de tinta produzidas na aldeia" (R.P. XERENTE, 2021). Além disso, na produção também são necessáriosoutros procedimentos pois:

A prática da produção primeiramente tem que limpá o capim dourado, (silêncio) eeeee lava, (silêncio) bem, com sabão, (silêncio) eeee,tambééééém, (silêncio). Pra trabalha com fita de buriti, temos queeee, as vezes comprá, e as vezes, temos queee (silêncio), i no brejo, pra pode (silêncio) cortaaa, e traze pra casa esse material, (silêncio) pra ser utilizado que é fita de buriti (S.V. XERENTE, 2021).

Se a prática da produção do artesanato a princípio era voltada para a produção de utensílios domésticos e não valorizada como produto de mercado (MELLO, 2014), hoje é diferente"é por meio desse mercado que a maioria da aldeia supre as necessidades com essas vendas, ou seja, para a compra de alimentos, porque não temos outra renda a não ser, né, a produção de artesanato e venda" (R. P. XERENTE, 2021). Devido à alteração dos costumes indígenas, colocando-os no caminho do mercado de consumo capitalista e a partir da "valorização" do artesanato, a produção hoje é voltada para geração de renda.

\begin{abstract}
Ééééé (silêncio) geralmente a genteeeee, a gente confecciona só pra, pra venda (silêncio), porqueee, como a maioria das famílias não, não são empregados, não tem éééééé, emprego, emprego fixo (silêncio), a genteeee, confecciona pra, pra venda mesmo, pro, pra, pra... pras necessidades diárias, nas, na alimentação né (silêncio) e assim, e pro uso próprio também as vezes a gente confecciona pro uso próprio, mas na maioria das vezes a gente confecciona pra venda, praaa, pro comércio (silêncio) (B.C. XERENTE, 2021).
\end{abstract}

E de acordo com V.G. Xerente (2021), esta realidade sofreu novas modificações devido à pandemia do COVID-19 na qual o "dia a diaaaaaa, (silêncio) hoje,(silêncio) ééééééé, (silêncio) por causa da pandemia, (silêncio) hoje a genteeeee, (silêncio) faz né, a gente faz as nossas ar, as nossas artesanatos cada uma em sua casa num ambiente ventilado, (silêncio) produzimos nossos artesanato". Nas pausas gramaticais regulares, é possível perceber a organização do pensamento, em torno do referencial que existia, mas que sofreu alterações, como uma construção da autoimagem que precisa negociar com o passado e o 
presente, mas também precisa de aprovação dos outros com a utilização do "né" (POLLACK, 1992).Do mesmo modo percebe-se a necessidade de revelar os cuidados que agora precisam manter devido à epidemia, quando revela sobre o ambiente de trabalho ventilado.

B.V. Xerente (2021) evidencia que cada Aldeia possui sua própria resposta frente aos obstáculos, como no caso da pandemia, na qual "tem muita gente que não pro... produziu mais, tem gente que tá produzindo sem, sem vendê, ai tem muita gente que parô, porque tava difícil, não podia leva pa vende, na cidade". Em outra aldeia foi falado que:

[...] a gente hoje, (silêncio) diante dessa situação mais uma vez, dessa pandemia. (silêncio) a gente teeem dividido nosso tempo, (silêncio) ééééé um pouco pra artesanato, e um pouca pra, (silêncio) roça, (silêncio) porque não tá sendo fácil, (silêncio) tudo caro, (silêncio) eeeeee as vezes nãooooo, (silêncio) compensa só a gente trabalha com artesanato (V.B. XERENTE, 2021).

As vozes aqui apresentadas indicam formas diferencias de vivenciar a produção e enfrentar as dificuldades geradas pela sociedade contemporânea dentro de uma cultura subjugada.Entretanto, possuem o mesmo entendimento de que o povo Akwê-Xerente passa por dificuldades e que a grande preocupação das entrevistadas, na verdade, encontra ressonância no viver junto, um entendimento relacionado à cultura que representam.

\section{Tramas da comercialização}

O povo Akwê-Xerente mantém relações significativas com a economia de mercado $^{18}$, vendendo ou consumindo bens e serviços em meio à imensa diversidade cultural e aos variados processos históricos vividos, incluindo as condições atuais. Desta forma, existem diversas estratégias pelas quais a comercialização de produtos oriundos da produção artesanal é vivenciada por esse povo na busca pela geração de renda.

De acordo com as entrevistadas, a importância reside no fato de "[...] desde sempre a gente já faz eee, é importante a gente não esquece, porque éééé a nossa arte, que a gente sempre fez e é também, o meio de nós acharmo dinheiro (silêncio) eeeeee (silêncio) mostrá pros branco o que a gente faz" (S.M. XERENTE, 2021). O silêncio pode ser considerado como uma defesa, uma forma de não revelar tudo (PORTELLI, 2000). "Éééééé a importância desse mercado (silêncio) de trabalhácoooommmm artesanato capim dourado (silêncio) ééééésomenteeeee (silêncio) pro sustento do povo Akwe, povo Akwe (silêncio) se sustenta com artesanato de capim dourado" (S. V. XERENTE, 2021).

\footnotetext{
${ }^{18}$ Sistema econômico elaborado no seio do desenvolvimento do capitalismo que tem como premissa básica a centralidade do mercado na economia, através da redução dos papéis exercidos pelo Estado. 
Demonstrando disposição de lembrar, de tempos, de pessoas, de situações vividas e resgatando a importância da atividade laboral que executa,elas continuam "[...] hojeeee a genteeee faz mais praaa, pra venda, pra ajuda no dia a dia, éééééé compra ossss alimento que precisa (silêncio) ééééé calçado, ajudando (silêncio) na vida financeira da casa" (V.G. XERENTE, 2021). Esta situação foi imposta por uma relação com o mercado que foi introduzida - e não criada por esse povo - por meio da produção e venda do artesanato, atividade essa que gera um complemento e muitas vezes configura o único sustento da Aldeia.

A construção de alternativas econômicas também enfrenta outras implicações que dizem respeito à comercialização, relacionadas à sua efetivação,fazendo com que este povo esteja num "[...] ambiente muito inadequado, um espaço muito aberto, sem muita organização, não é um lugar apropriado, (silêncio) é um antigo posto de gasolina, não tem uma lugar adequado, (silêncio) tanto que quando chove atrapalha a venda" (R.P. XERENTE, 2021).Alterações e adaptações do próprio cotidiano ${ }^{19}$ ao cotidiano da sociedade formal,pois

[...] é muito assim difícil por não ter o espaço, e o porquê dá gente não tá incluído, hummm a gente ter uma forma mais digna de venda (silêncio) e não ter as venda a onde a gente busca e procura pessoas pra compra no espaço inadequado, livre e nos dias que (silêncio) esse dia é um dia pra ser (silêncio) aproveitado trabalhando e não fazendo fera nos dias de segunda (V.G. XERENTE, 2021).

Ao revelar as dificuldades enfrentadas, demonstra a ausência do lugar adequado para a venda da produção, como também a utilização de um dia que não parece ser favorável à própria tradição.Para B.V. Xerente (2021), as vendas "[...] no nosso estado são realizadas em Tocantínia numa feirinha" que para ela parece ser "uma feira que, que éééé, é um improviso", pois elas "não têm lugar próprio pra vender".Utilizando Escobar (2017) na interpretação, percebe-se a imposição da imagem estruturada de lugares dos países de primeiro mundo, objetivando uma medida estabelecida, a da economia de desenvolvimento ocidental estabelecida nas tramas da produção capitalista racionalizada, que impõe à produção do trabalho códigos de significação da vida social, e que não atende aos padrões mínimos de um ambiente de comércio saudável e seguro.

É perceptível entre os Akwê o sentimento de pertencimento, de territorialidade, um simbolismo que marca sua tradição e que foi formado pelo agrupamento das partes, e que é visível por meio das falas

[...] pertencemos ao município de Tocantínia (silêncio) a venda, acontece na (silêncio) na feira semanalmente, toda segunda-feira (silêncio) temos a feira em Tocantínia, mas também, éééé (silêncio) acontece na aldeia também, porque muitos compradores vão, na, na,

\footnotetext{
${ }^{19}$ Que é habitual ao ser humano, ou seja, está presente na vivência do dia a dia. 
nas aldeias, e ai a gente vende os nossos artesanatos, e também, éééé rola a, a troca (silêncio) muitos levam éééé alimentos e ai acontece a troca do artesanato (B.C.XERENTE, 2021).

Percebe-se que o discurso de alteridade ${ }^{20}$ na maioria das vezes é negado e usurpado, pois, conforme dito anteriormente, eles são discriminados. Tanto no que sentem, como por meio das ações do mercado capitalista que foi imposto ao povo Akwê, uma vez que no mercado do povo "não indígena" não é verificado o escambo, a troca de produtos por alimentos, e sim o dinheiro. Ainda que

[...]particularmente, eu não vejo issooo (silêncio) ansim (silêncio) ruim porqueeeee a necessss, a nossa necess, a necessidade de Akwê é muito grande, então si alguém vinher com, com alimento e eles estão com artesanatos, então eles trocam mesmo, porque ééééé eles (silêncio) trabalham com artesanato pro sustento deles né, então é (silêncio) a troca de artesanato pra troca de alimentos (silêncio) pra mim não é, não é ruim, é questão de sobrevivência eeeeee (silêncio) e na venda também, é muito bom pra gente vende porque, quando a gente vende artesanato a gente compra o que quer, vai no comercio e compra tudo que a gente quis é né, com o dinheiro do artesanato (silêncio) já na troca é bem diferente a pessoa não troca como que (silêncio) como quis (S.V.XERENTE, 2021).

Não ver problemas, não significa que eles não existam, tanto que ao final da fala revela o impedimento de realizar as próprias vontades quando precisa optar pela troca ao invés do dinheiro. Todavia, para muitos a situação gera desconforto pois

É preciso ser valorizado aham, nois vive de artesanato, nois tinha que ter um, $[\ldots]$, tinha que te o nosso protocolo de preços mesmo, igual os branco tem, os branco tem os preço, ele já vende as coisa pra nois, nois ai sabe só abaxa um centavo, ou alguma coisinha, e o nosso não eles qué que bota, as veze até pegam o que o preço seu nem espera que a gente vai colocá o nosso preço, vai dize o nosso preço, esse exemplo (B.V.XERENTE, 2021).

Não decidir o preço do seu produto, não ter o preço do próprio produto protegido pelo governo - apesar das regras criadas no sentido de 'proteger' esses povos - ou pelo mercado, e seguir consentindo, como seus antepassados quando foram colonizados. Já que muitos

\footnotetext{
${ }^{20}$ Reconhecimento de que existem pessoas e culturas singulares e subjetivas que pensam, agem e entendem o mundo de suas próprias maneiras. 
[...] somos obrigados [...] eu não tenho renda (silêncio) não tenho renda fixa (silêncio) e o meu meio de, de, de, de renda é o artesanato (silêncio) eeeeeee na maio, na maioria das vezes, ééééé (silêncio) mesmo a gente não querendo vender com, com preço muito (silêncio) a baixo (silêncio) a baixo do, do esperado, a gente tem que vender porque a necessidade é grande né, né, em termos de alimentação (silêncio) e aiiii, não só a alimentação também, mas o outros, é roupa, calçado, que nossas crianças precisa a gente (silêncio), si obriga a vender, e é isso que a gente vê, na, na minha opinião, eu vejo (B.C. XERENTE, 2021).

É perceptível o entendimento que possuem do mercado e seu funcionamento, assim também como a posição que ocupam nesta trama.Seja como extratores de matéria prima ou modeladores de artefatos, são subjugados por um mercado no qual o preço de seu trabalho e produção é imposto pela "mão invisível". Contudo, para esse povo não seguem as mesmas regras, as regras do mercado "não indígena" para venda não são as mesmas para os indígenas. Quando falamos sobre as peças mais procuradas, foi-nos revelado que

As mais procurada hoje, por ela não ter valor (silêncio) que ainda permanece, não ééééé (silêncio) os que geralmente usss atravessadores buscam, e compram pelo mesmo preço que não tem a tabela, que a gente precisaria muito diiiii uma organização, que nos ajudasse por exemplo: a mandala (silêncio), ela já tem muito tempo que ela custa dois reais (silêncio), independente do seu tamanho que seja grande, pequena, mas ela custa esse mesmo valor (silêncio), então por ela ser a mais pedida pelo preço ela ééé mais utilizada', e ai eeee (silêncio) é a mais trabalhada (silêncio) pras artesã (V.G. XERENTE, 2021).

Então, a lei máxima da oferta e procura para os indígenas é diferente.Maior procura, maior preço essa é a regra do livre mercado.Contudo, para os povos indígenas, mais matéria prima e mais horas gastas para executar a atividade não representa maior valor de troca ou lucro.Ainda que a apropriação dos artefatos indígenas por pessoas não indígenas ocorra por funções distintas, o curso das relações com o mercado deveria ser interpretado com a autenticidade das experiências de objetificação do mercado. Porém, temos um retrato do pensamento abissal ${ }^{21}$, no qual o pensamento de igualdade entre os cidadãos esconde desigualdades brutais (SANTOS, 2007). Uma realidade vivida todos os dias e por meio de várias experiências

\footnotetext{
${ }^{21}$ Característica da modernidade ocidental, que consiste num sistema de distinções visíveis e invisíveis que divide a realidade social em dois universos ontologicamente diferentes. 
Primeiramente é, eu sinto e vejo que a desvalorização é muito grande (silêncio) porque (silêncio) em Goiânia, e não só em Goiânia em outras cidades que eu já tive (silêncio) quando eu entrei no Shopping e vi uma peça, uma peça de, de (silêncio) de artesanato de capim dourado que dá minha mão foi comprado por um preço baixo (silêncio) e quando eu vi no Shopping vi, eu fiquei muito (silêncio) muito surpresa com o preço né, né porquê ahhh. quando os compradores compram das nossas mãos eles não valorizam (silêncio) e quando chega na vitrine (silêncio) a gente vê como eles, pra eles, eles valorizam né, pra no seu bolso, mais pra nossa, pra nós, pro nosso esforço eles não veem, então a desvalorização é muito grande (silêncio) e que precisava ser, e precisa ser valorizado, a oooo artesanato capim dourado (B.C. XERENTE, 2021).

De acordo com Miglieviche (2016), aqui temos um 'giro decolonial 22 ' personificado no discurso crítico implementado nesses povos, mas que traz a colonialidade embutida na imposição da forma de negociação dos próprios produtos que expõem o lado colonial do sistema mundial moderno. E essas dificuldades assumem proporções maiores quando essa inserção é afrontada com a pandemia do COVID-19

[...] depois da pandemia é... (silêncio) por causa do decreto do município proibindo aglomerações, não houve mais esse, essa feira né que era como antes da pandemia porque muitos compradores não vinha mais (silencio) e isso tornou o acesso mais difícil (silêncio) e antes da pandemia também alguns dos Xerentes iam pra feira de To, de, de Palmas, feira do Bosque (silêncio) e de lá vinham e passavam na segunda-feira em Tocantínia (silêncio) e... depois da pandemia isso não aconteceu mais, [...] a dificuldade é muito grande né, porque muitos compradores não que vir, a gente não tem essa condição de leva em outras cidades, e em muitos lugares aglomeração não é permitido (silêncio) eeeee isso sofreu muito alteração na, na com relação a venda de artesanato (silêncio) e mesmo assim a gente tááááá, tá produzindo sim né, e mesmo com preço muito diferente, muito baixo, mas mesmo assim a gente (silêncio) confecciona ainda produtos sim, artesanato (B.C. XERENTE, 2021).

Aspectos que requerem atenção e cuidado por parte do governo que, conforme dito anteriormente, regulamenta e intervém diretamente nesse povo, mas que num contexto tão assimétrico tem escapado dos objetivos imediatos, apesar de serem partes fundamentais de uma diversa e complexa cadeia de relações sociais e significados que carregam.

\footnotetext{
${ }^{22}$ Termo utilizado originalmente por Maldonado-Torres (2005) que significa o movimento de resistência teórico e prático, político e epistemológico, à lógica da modernidade/colonialidade (BALLESTRIN, 2013). FREIESLEBEN, Mariane; XERENTE, Janaina Sikwatkadi Calixto; SILVA, Alex Pizzio da; SILVA, Reijane Pinheiro da. O mercado de artefatos Akwê-Xerente: Contextos urbanos em período de covid-19. Espaço Ameríndio, Porto Alegre, v. 15, n. 2, p. 182-205, mai./ago. 2021.
} 
Antes da pandemia né, era mais fácil de vender artesanato (silêncio) porque toda segunda-feira, toda semana já tinha uma data definida né (silêncio) pra levar artesanato e vender (silêncio) já que a maioria das pessoas que produz artesanato vendia na cidade, mas com essa pandemia dificultou muito porque pelo decreto né, municipal foi cancelada as ferinhas de artesanato né, que era nos dias de segunda e que por muito tempo não aconteceu (silêncio) e também os compradores que são não indígenas ia até na aldeia comprar artesanatos pra revenda, mas com essa pandemia né, respeitando aglomeração, até mesmo pelo decreto mesmo da FUNAI, é que foi proibida a entrada de pessoas não indígenas na aldeia, que pra não correr o risco de contamina os indígenas, então nisso dificultou muito (silêncio) mas algumas pessoas ainda conseguem vender pelas redes sociais como Whatzapp, Instagram, mas para nós isso foi impossível (R.P. XERENTE, 2021).

Essa comercialização precisa considerar e ser considerada tendo em vista sua participação no processo de produção e comercialização, que carrega implícitas relações econômicas e sociais diferenciadas, de forma que estas não sejam prejudicadas devido às dificuldades impostas pela contemporaneidade, cedendo espaço para o que Mignolo (2005), em seu escrito, conceitua de "imaginário", ou seja, uma construção que leva em conta a comunidade e que parte da imagem interna da produção dos participantes, pois essa atividade representa para eles muito mais que um ganho material, mas o sustento da Aldeia.

\section{Considerações finais}

Os desafios enfrentados pelos Akwê durante a pandemia extrapolam os riscos para a saúde, uma vez que os entrevistados apontam a impossibilidade de comercialização do artesanato produzido, uma das principais fontes de renda das famílias Xerentes. Os artefatos/artesanatos são produzidos a partir de lógicas culturais que retratam práticas sociais, modos de conhecimento e relações de poder que foram construídos ao longo da história do povo Akwê-Xerente.

Os órgãos dos governos federal, estadual e municipal, ignoram as dificuldades socioeconômicas, políticas e até mesmo jurídicas dos artesãos indígenas, que, fiéis às próprias tradições, desenvolvem um trabalho artesanal. A própria venda de seus produtos é controlada pelos compradores, que forçam preços irrisórios ou a prática do escambo a uma produção que preserva cultura e conhecimentos tradicionais. Nesse sentido, o povo Akwê-Xerente desponta não somente como um povo desassistido num contexto de pandemia da COVID-19, mas como um povo de resistência ao instigar a reflexão sobre a opressão socioeconômica a que são expostos por parte da própria sociedade 
que, ao descriminar, reduz a visibilidade desse povo, dessa cultura e o conhecimento de seu modo de vida e dos desafios enfrentados.

Torna-se necessário promover um amplo debate social acerca da produção e comercialização do artesanato indígena, de forma a garantir os direitos dessa produção, sem que haja desrespeito a esse povo. Nesse debate, é fundamental que se coloque também o foco na forma como governos municipais, estaduais e federal incentivam essa produção e como evitar os efeitos socioeconômicos deletérios de sua comercialização, fatores muitas vezes ignorados, mas que conduzem o indígena à posição de miserabilidade.

O povo Akwê-Xerente deve ter o direito de produção e comercialização de seu artefato/artesanato garantido. É importante nos questionarmos, portanto, se o processo de comercialização da produção artesanal não acaba reproduzindo procedimentos de exploração inseridos em antigas práticas coloniais, que já deveriam ter sido banidas, tomando por base o conhecimento que já acumulamos e, principalmente, reconhecendo o prejuízo que tais práticas subsidiaram a esse povo. 
EspaçoAmeríndio

\section{Referências bibliográficas}

ALBERTI, Verena. Manual de história oral. Ed. 3 . Rio de Janeiro: Editora FGV. 2005.

ALBUQUERQUE, Marcos Alexandre dos Santos. Indígenas na Cidade do Rio de Janeiro. Cadernos do Desenvolvimento Fluminense, 7:149-168, 2015.

ALDEIAS: B.C. XERENTE; B. V. XERENTE; R. P. XERENTE; S. M. XERENTE; S.V. XERENTE; V. G. XERENTE. Entrevista concedida a Janaina Sikwatkadi Calixto Xerente, Tocantínia - Aldeias Akwe-Xerente, Jan/Fev. 2021.

ARAUJO, Rosemary Negreiro de. Os territórios, os modos de vida e as cosmologias dos indígenas Akwẽ-Xerente, e os impactos da uhe de lajeado. 312f. Tese (Doutorado em Geografia) - Programa de Pós-Graduação em Geografia, do Centro de Ciências, da Universidade Federal do Ceará. Fortaleza, 2016.

BALleStRIN, Luciana. América Latina e o giro decolonial. Revista Brasileira de Ciência Política (Impresso), v. 2, p. 89-117, 2013.

BRASIL. Constituição (1988). Constituição da República Federativa do Brasil. Brasília, DF: Senado, 1998.

DUQUE, Felipe da Silva. Economia criativa: empreendimentos culturais. In: LiaCalabre de Azevedo; Maurício Siqueira; Deborah Ribeiro Lima; AdéliaZimbrão (org.), Anais do VI Seminário Internacional de Políticas Culturais. Rio de Janeiro, Fundação Casa de Rui Barbosa, p. 487-497, 2015.

DUSSEL, Enrique. Europa, modernidade e eurocentrismo. In: Edgardo Lander (coord.). A colonialidade do saber: eurocentrismo e ciências sociais - perspectivas latinoamericanas. Buenos Aires: Clacso, 2005.

ESCOBAR, Arturo. La invencion del tercer mundo. Fundación Editorial El Perro y la Rana: Caracas, Venezuela, 2017.

JESUS, Diego Santos Vieira de. Economia criativa e resistência: o artesanato indígena no Estado do Rio de Janeiro. Revista Ciências Sociais Unisinos, v. 53, p. 349-362, 2017.

LIMA, Antônio Carlos de Souza. O Governo dos índios sob a Gestão do SPI. In: ManuelaCarneiro da Cunha. (org.) História dos Índios no Brasil. São Paulo: Companhia das Letras: Secretaria Municipal de Cultura: FAPESP, 1992.

LIMA, Layanna Giordana Bernardo. Os Akwẽ-Xerente no Tocantins: território indígena e as questões socioambientais. 320f. Tese (Doutorado em Geografia) - Faculdade de Filosofia, Letras e Ciências Humanas da Universidade de São Paulo. São Paulo, 2017.

MELLO, Janaina Cardoso de. A cultura Xerente e seu artesanato dourado. Patrimônio, memória e registro na região do Jalapão? Tocantins. Patrimônio e Memória (UNESP), v. 10, p. 75-90, 2014. 
EspaçoAmeríndio

MESQUITA, Rodrigo. Indígenas em contexto urbano, conflitos socioculturais e linguísticos: o exemplo dos Akwẽ-Xerente. Revista de Ciências Humanas, Florianópolis, v. 49, n. 2, p. 143-162, jul-dez 2015.

MIGLIEVICH, Adelia. Intelectuais e epistemologia crítica latino-americana: do anticolonial ao decolonial. Rassegna iberistica, v. 39, p. 117-128, 2016.

MIGNOLO, Walter D. A colonialidade de cabo a rabo: hemisfério ocidental no horizonte conceitual da modernidade. In: Edgardo Lander (coord.). A colonialidade do saber: eurocentrismo e ciências sociais - perspectivas latino americanas. Buenos Aires: Clacso, 2005.

MOREIRA, Elaine; GOUVEIA, Rachel; GARCIA, Joana; ACOSTA, Luis; BOTELHO, Marcos; ROCRIGUES, Mavi; KRENZINGER, Miriam; BRETTAS, Tatiana. Em tempos de pandemia: propostas para a defesa da vida e dos direitos sociais. Rio de Janeiro: UFRJ, Centro de Filosofia e Ciências Humanas, Escola de serviço social, 155p., 2020 .

OLIVEIRA-REIS, Francisco Carlos. ASPECTOS DO CONTATO E FORMASSOCIOCULTURAIS DA SOCIEDADE AKWË-XERENTE(JÊ). 120f. Dissertação (Antropologia Social) - Departamento de Antropologia do Instituto de Ciências Sociais da Universidade de Brasília. Brasília-DF, 2001.

POLLAK, Michael. Memórias e identidade social. Estudos Históricos, Rio de Janeiro, vol. 5, n. 10, 1992, p. 200-212.

PORTAL TOCANTINS. Governo do estado leva mensagem de apoio a criação do centro de fortalecimento da cultura Xerente. 11/10/2019. Disponível em: $<$ https://portal.to.gov.br/noticia/2019/10/11/governo-do-estado-leva-mensagem-deapoio-a-criacao-do-centro-de-fortalecimento-da-cultura-xerente/ $>$ Acessado em: 22/01/2021.

PORTELI, Allessandro. O que faz a história oral diferente. Proj. História, São Paulo, 1997, p. 25-39.

PORTELI, Allessandro. Memória e dialogo: desafios da história oral para a ideologia do século XXI. In: FERREIRA, M. de M.; FERNANDES, T. M.; ALBERTI, V. História Oral: desafios do século XXI. Rio de Janeiro: Editora Fiocruz, 2000.

QUIJANO, Aníbal. Dom Quixote e os moinhos de vento na América Latina. Estudos Avançados (USP), 19(55), 2005.

RAPOSO, Clarisse Marina dos Anjos. Sobre voragem e fertilidade: parentesco, nominação e alteridade nos modos Akwẽ-Xerente de composição da vida. 351f. Tese (Doutorado em Antropologia) - Universidade Federal de Minas Gerais, Faculdade de Filosofia e Ciências Humanas. Belo Horizonte, 2019.

RAG/FUNAI - Relatório Anual de Gestão. Fundação Nacional do Índio - 2018. BrasíliaDF. Disponível em: $<$ http://www.funai.gov.br/arquivos/conteudo/cgge/Pdf/relatoriogestao-2018-Funai-1.pdf $>$ Acessado em: 22/01/2021. 
REIS, Ana Carla Fonseca. Introdução. In: Ana Carla Fonseca Reis (org.), Economia criativa como estratégia de desenvolvimento: uma visão dos países em desenvolvimento. São Paulo, Itaú Cultural, p. 14-49, 2008.

RIBEIRO, Darcy. Os índios e a civilização: a integração das populações indígenas no Brasil moderno. São Paulo: Companhia das Letras, 1996.

ROCHA, Leandro Mendes. A política indigenista como objeto de estudo: 19301967. História Revista, v. 1, n. 1, 22 ago. 2010.

ROQUE, Lucas; TERENA, Marcos; CALFIN, Juan Antonio; TERENA, Taily. Jogos mundiais dos povos indígenas: Brasil, 2015: o importante é celebrar! Brasília: PNUD, 2017

SANTOS, Boaventura de Sousa. Para além do Pensamento Abissal: Das linhas globais a uma ecologia de saberes. Coimbra: Revista Crítica de Ciências Sociais, no 78, pp. 3-46, outubro de 2007.

SILVA, Reijane Pinheiro da; GRACIO, Héber Rogério. O modelo de desenvolvimento do tocantins e o povo akwẽ-xerente: impactos socioambientais e desafios da interculturalidade. Pracs: revista eletrônica de humanidades do curso de ciências sociais da Unifap, v. 13, p. 131-144-144, 2020.

SOARES, Khellen Cristina Pires C.; DEBORTOLI, José Alfredo Oliveira. Indígenas Akwe-Xerente: territorialidade, Sustentabilidade e Lazer. ATHLOS. Revista Internacional de Ciencias Sociales de la Actividad Física, el Juego y el Deporte, v. XIV, p. 1-28, 2018.

VERETA-NAHOUM, André; GUIMARÃES, Nadya Araujo. Apresentação: Explorando os sentidos sociais da economia. Tempo Social, v. 29, p. 1-22, 2017.

Recebido em: 14/04/2021* Aprovado em: 09/08/2021 * Publicado em: 30/08/2021 